\section{Novel Glycolipids; Cellobiosylsterol and Cellotriosylsterol in Rice Bran}

\author{
Masao OHNisH and Yasuhiko FuıINo \\ Department of Agricultural Chemistry, Obihiro \\ University of Agriculture and Veterinary \\ Medicine, Obihiro, Hokkaido
}

Received October 6, 1978

In a previous paper, ${ }^{1)}$ we described in detail the chemical composition of sterol lipids (free 4, 4-dimethylsterol, 4-monomethylsterol, 4-desmethylsterol, sterylester, sterylglycoside and acylsterylglycoside) in rice bran, and discussed the possible structural and metabolic relations of these sterol lipids. In recent examination thereafter of the alkali-stable glycolipid fraction from rice bran, we obtained evidence for the presence of small amounts of novel sterylglycosides containing oligosaccharide moieties (mainly diglycosylsterol and triglycosylsterol). ${ }^{2}$ In this communication we report preliminarily the chemical structures of these novel glycolipids.

Rice bran was extracted with chloroformmethanol $(2: 1, \mathrm{v} / \mathrm{v})$ and water-saturated butanol to obtain total lipids as described previously. ${ }^{1)}$ The lipids were subjected to silicic acid column chromatography by sequential elution with chloroform, acetone and methanol. ${ }^{3}$ The glycolipid fraction eluted with acetone was then treated with mild alkali to remove the contaminating glycerolipids. ${ }^{4}$ When the alkali-stable glycolipid fraction obtained was subjected to silica gel $G$ thin-layer chromatography with chloroform-methanolwater $(65: 25: 4, \mathrm{v} / \mathrm{v} / \mathrm{v})$, at least three spots ( $R f: 0.57,0.53$ and 0.29 ), giving a color reaction characteristic for sterol with sulfuric acid, were found in addition to several sphingolipid $^{4}$ ) and the well-known sterylglycoside (monoglycosylsterol, $R f: 0.75$ ). ${ }^{1} \quad$ These spots were tentatively recognized from their $R f$ values as diglycosylsterol ( $R f: 0.57$ and 0.53 ) and triglycosylsterol $(R f: 0.29)$. The alkalistable glycolipid fraction was then subjected to silicic acid column chromatography with a stepwise elution of chloroform and methanol, preparative silica gel $G$ thin-layer chromatography and acetylation to purify the two sterylglycosides.

The infrared spectra of diglycosylsterol and triglycosylsterol thus isolated resembled that of monoglycosylsterol. ${ }^{11}$ A broad absorption band $\left(1125 \sim 1000 \mathrm{~cm}^{-1}\right)$ due to the alcoholic C-O of sugar was observed, the intensity being least in monoglycosylsterol and greatest in triglycosylsterol. An absorption peak due to $\beta$-glycosidic linkage was also seen near 900 $\mathrm{cm}^{-1}$ in all the sterylglycosides.

When the lipophilic and water-soluble fractions prepared from the complete hydrolysis of diglycosylsterol and triglycosylsterol with methanolic $1 \mathrm{~N} \mathrm{HCl}$ for $3 \mathrm{hr}$ at $100^{\circ} \mathrm{C}$, were analyzed by gas-liquid chromatography, silica gel $G$ thin-layer chromatography and paper chromatography, only sterols and hexose were found in both the sterylglycosides, respectively. Assay of the two constituents by gas-liquid chromatography using inositol and cholestane as internal standards revealed that these units were present with approximate molar ratios of $1: 2$ and $1: 3$ in diglycosylsterol and in triglycosylsterol, respectively. When each oligoglycosylsterol was heated under reflux with $0.2 \mathrm{~N}$ $\mathrm{HCl}$ for $2 \sim 6 \mathrm{hr}$, only D-glucose was detected in the water-soluble fraction. Analysis of the lipophilic fraction showed the presence of a continuous series of partially-deglycosylated derivatives.

The sterol composition in sterylglycosides analyzed by gas-liquid chromatography (column packing; $1.5 \% \mathrm{SE}-30$, column temperature; $230^{\circ} \mathrm{C}$ ) is shown in Table I. In each case, the predominant components were $\beta$ sitosterol, campesterol and stigmasterol, which were confirmed by gas chromatography-mass spectrometry. ${ }^{11}$

For the determination of the anomeric configuration of the glycosidic linkages in sterylglycosides, the acetyl derivatives were oxidized with chromium trioxide in acetic acid for $45 \mathrm{~min}$ at $50^{\circ} \mathrm{C.}^{5)}$ Upon methanolysis and gas-liquid chromatography (column packing; $1.5 \% \mathrm{SE}-$ 
TABle I. Composition of Sterols IN STERYLGLyCOSIDES FROM RICE BRAN (\%)

\begin{tabular}{lccc}
\hline \multicolumn{1}{c}{ Sterol } & $\begin{array}{c}\text { Monoglyco- } \\
\text { sylsterol }\end{array}$ & $\begin{array}{c}\text { Diglyco- } \\
\text { sylsterol }\end{array}$ & $\begin{array}{c}\text { Triglyco- } \\
\text { sylsterol }\end{array}$ \\
\hline Cholesterol & 1.1 & 1.9 & 2.8 \\
Campesterol & 10.7 & 17.2 & 13.8 \\
Stigmasterol & 13.0 & 12.3 & 9.7 \\
$\beta$-Sitosterol & 70.7 & 66.1 & 72.6 \\
$A^{3}$-Avenasterol & 1.3 & 0.3 & 0.8 \\
$\Delta^{7}$-Stigmastenol & 0.7 & 0.5 & $<0.1$ \\
$A^{7}$-Avenasterol & 1.8 & 1.4 & 0.3 \\
Others & 0.7 & 0.3 & $<0.1$ \\
\hline
\end{tabular}

30 , column temperature; $170 \sim 200^{\circ} \mathrm{C}$ at $3^{\circ} \mathrm{C} /$ $\mathrm{min}$ ), recoveries of methylglycosides in the oxidized diglycosylsterol and triglycosylsterol were found to be $14 \%$ and $5 \%$, respectively. These imply that the glucose units of both sterylglycosides should be mainly linked $\beta$ glycosidically with monoglycosylsterol. ${ }^{\text {b) }}$

In order to examine the positions of the glycosidic linkages, oligoglycosylsterols were permethylated $^{6}$ ) and the products were purified by silica gel $\mathrm{G}$ thin-layer chromatography with chloroform-benzene-acetone $(80: 20: 10, \mathrm{v} / \mathrm{v} / \mathrm{v})$. When the permethylated diglycosylsterols were analyzed by direct inlet mass spectrometry (Fig. 1), the relative intensities of the fragment

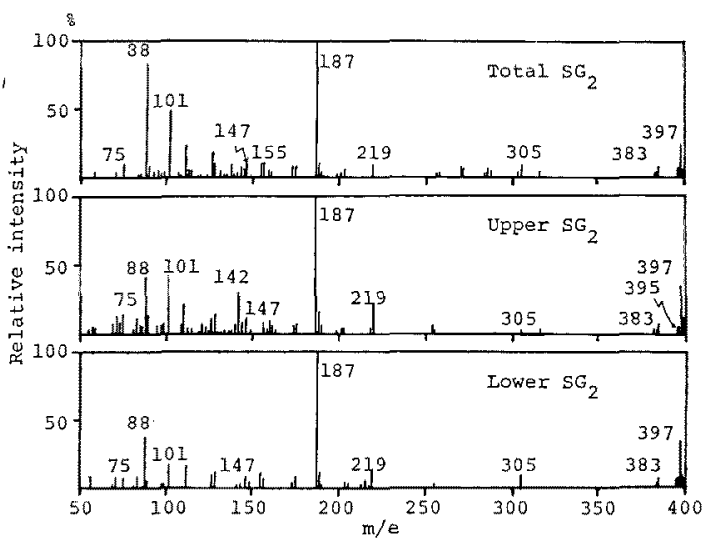

FIG. 1. Mass Spectra of the Permethyl Derivatives of Diglycosylsterol $\left(\mathrm{SG}_{2}\right)$ from Rice Bran.

ions $(m / e 88,101,147 \text { etc. })^{7}$ derived from the permethylated hexose were considerably different from each other in the mass spectra of two diglycosylsterols with $R f: 0.57$ and 0.53 . There- fore, the position of the internal-glycosidic linkage was considered to be different from each other in the two diglycosylsterols.

The permethylated sterylglycosides were then methanolyzed. The methanolic solution after extraction of sterols was treated with ion exchange resin and evaporated to dryness to yield methylated methylglycosides. When the methylated sugars from diglycosylsterol were analyzed by gas-liquid chromatography (column packing; Diasolid ZF, column temperature; $190^{\circ} \mathrm{C}$ ), peaks derived from a terminal glucopyranose unit and an internal 1, 4-substituted glucopyranose unit were observed in diglycosylsterol with $R f: 0.53$. On the other hand, the methylated sugars from diglycosylsterol with $R f: 0.57$ gave the peaks derived from a terminal glucopyranose unit and an internal 1, 3-substituted glucopyranose unit.

A part of the methylated sugars were converted to partially-methylated acetylalditols with acid hydrolysis and reduction followed by acetylation, as described previously. ${ }^{4}$ When the partially-methylated acetylalditols prepared from the two diglycosylsterols and triglycosylsterol were analyzed by gas chromatography-mass spectrometry (column packing; Diasolid ZT, column temperature; $190^{\circ} \mathrm{C}$ ), the mass spectra indicated the presence of $2,3,4,6$ tetra-O-methyl-1, 5-di-O-acetyl-glucitol, 2, 3,6tri-O-methyl-1, 4, 5-tri-O-acetyl-glucitol and 2, 4, 6-tri-O-methyl-1, 3, 5-tri-O-acetyl-glucitol in both cases. ${ }^{8}$ The ratios of the latter two peak areas were found to be $78: 22$ in diglycosylsterols and 93:7 in triglycosylsterol, respectively.

Based on the above findings, the major structure of $R f: 0.53$ diglycosylsterol, $R f: 0.57 \mathrm{di}-$ glycosylsterol and triglycosylsterol in rice bran were characterized as D-glucopyranosyl- $(\beta 1 \rightarrow$ $4)$ - D - glucopyranosyl - $\left(\beta 1 \rightarrow 3^{\prime}\right)$ - $\beta$-sitosterol, Dglucopyranosyl- $(\beta 1 \rightarrow 3)$ - D-glucopyranosyl- $(\beta 1$ $\left.\rightarrow 3^{\prime}\right)$ - $\beta$-sitosterol and D-glucopyranosyl- $(\beta 1 \rightarrow$ 4)-D-glucopyranosyl- $(\beta 1 \rightarrow 4)$ - $D$-glucopyranosyl- $\left(\beta 1 \rightarrow 3^{\prime}\right)-\beta$-sitosterol, respectively.

Diglycosylsterol was previously isolated from green tea and its major structure was tentatively characterized as gentiobiosyl- $\alpha$-spina- 
sterol. ${ }^{9)} \quad$ However, the presence of $\beta 1 \rightarrow 6$ bond could not be detected in rice bran diglycosylsterols. Triglycosylsterol has never been reported to be present in any natural source, although Radwan et al. suggested that oligoglycosylsterols containing two to six moles of sugar were present in plant tissue cultures. ${ }^{10)}$

Details of the studies will be published elsewhere.

Acknowledgement. This work was supported in part by a grant for Scientific Research in 1977 from the Ministry of Education of Japan.

\section{REFERENCES}

1) N. Kuroda, M. Ohnishi and Y. Fujino, Cereal Chem., 54, 997 (1977).
2) M. Ohnishi, S. Ito and Y. Fujino, Proceedings of Japanese Conference of the Biochemistry of Lipids, 20, 299 (1978).

3) G. Rouser, G. Kritchevsky, S. Simon and G. J. Nelson, Lipids, 2, 37 (1968).

4) Y. Fujino and M. Ohnishi, Chem. Phys. Lipids, 17, 275 (1976).

5) R. A. Laine and O. Renkonen, J. Lipid Res., 16, 102 (1975).

6) E. P. Adams and G. M. Gray, Chem. Phys. Lipids, 2, 147 (1968).

7) N. K. Kochetkov, N.S. Wulfson, O.S. Chizhov and B. M. Zolotarev, Tetrahedron, 19, 2209 (1963).

8) H. Björndal, C. G. Hellerqvist, B. Lindberg and S. Svensson, Angew. Chem., 9, 610 (1970).

9) I. Khanna, R. Seshadri and T. R. Seshadri, Phytochemistry, 13, 199 (1974).

10) S. S. Radwan, F. Spener, H. K. Mangold and E. J. Staba, Chem. Phys. Lipids, 14, 72 (1975). 